\title{
A performance assessment of the World Wide Lightning Location Network (WWLLN) via comparison with the Canadian Lightning Detection Network (CLDN)
}

\author{
D. Abreu ${ }^{1}$, D. Chandan ${ }^{1}$, R. H. Holzworth ${ }^{2}$, and K. Strong ${ }^{1}$ \\ ${ }^{1}$ Department of Physics, University of Toronto, Ontario, Canada \\ ${ }^{2}$ Departments of Earth and Space Sciences, and Physics, University of Washington, Washington, USA
}

Received: 12 March 2010 - Published in Atmos. Meas. Tech. Discuss.: 20 April 2010

Revised: 20 August 2010 - Accepted: 20 August 2010 - Published: 27 August 2010

\begin{abstract}
The World Wide Lightning Location Network (WWLLN) uses globally-distributed Very Low Frequency (VLF) receivers in order to observe lightning around the globe. Its objective is to locate as many global lightning strokes as possible, with high temporal and spatial $(<10 \mathrm{~km})$ accuracy. Since detection is done in the VLF range, signals from high peak current lightning strokes are able to propagate up to $\sim 10^{4} \mathrm{~km}$ before being detected by the WWLLN sensors, allowing for receiving stations to be sparsely spaced.

Through a comparison with measurements made by the Canadian Lightning Detection Network (CLDN) between May and August 2008 over a $4^{\circ}$ latitude by $4^{\circ}$ longitude region centered on Toronto, Canada, this study found that WWLLN detection was most sensitive to high peak current lightning strokes. Events were considered shared between the two networks if they fell within $0.5 \mathrm{~ms}$ of each other. Using this criterion, 19128 WWLLN strokes (analyzed using the Stroke_B algorithm) were shared with CLDN lightning strokes, producing a detection efficiency of $2.8 \%$. The peak current threshold for WWLLN detection is found to be $\sim 20 \mathrm{kA}$, with its detection efficiency increasing from $11.3 \%$ for peak currents greater than $20 \mathrm{kA}$ to $75.8 \%$ for peak currents greater than $120 \mathrm{kA}$. The detection efficiency is seen to have a clear diurnal dependence, with a higher detection efficiency at local midnight than at local noon; this is attributed to the difference in the thickness of the ionospheric D-region between night and day. The mean time difference (WWLLN-CLDN) between shared events was $-6.44 \mu \mathrm{s}$ with a standard deviation of $35 \mu \mathrm{s}$, and the mean absolute location accuracy was $7.24 \mathrm{~km}$ with a standard deviation of $6.34 \mathrm{~km}$. These results are generally consistent with previous
\end{abstract}

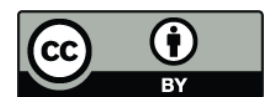

Correspondence to: K. Strong (strong@atmosp.physics.utoronto.ca) comparison studies of the WWLLN with other regional networks around the world. Additional receiver stations are continuously being added to the network, acting to improve this detection efficiency.

\section{Introduction}

There are many regional lightning detection networks operating around the world, providing data for purposes as varied as the prevention of lightning damage to sensitive equipment, the early detection of forest fires, and the tracking of local severe weather. They are used frequently for aviation operations, shipping routes, safety applications, and by sporting groups. Moreover, they are also employed by the insurance industry and electric utilities for insurance claims investigations and detecting power line fault locations (Cummins et al., 1998a). Meteorological agencies and research institutions use the data for studies dealing with indicators of climate change through seasonally and yearly averaged statistics (Williams, 1992; Schlegel et al., 2001; Price, 2009), studies dealing with the role lightning plays in determining atmospheric composition (e.g., Volland, 1984; Choi et al., 2005; Sioris et al., 2007; Martin et al., 2007), and for a priori information in weather forecasting models.

Although such regional lightning detection networks exist in many parts of the world and provide real-time data (e.g., Cummins et al., 1998b; Burrows et al., 2002; Cummins and Murphy, 2009; Höller et al., 2009; Lagouvardos et al., 2009), they generally provide limited spatial coverage, typically ending near national boundaries, and are unable to provide lightning data over the ocean. Lightning detection instruments also exist on orbiting satellites, such as the Optical Transient Detector (OTD; Christian et al., 2003) and the

Published by Copernicus Publications on behalf of the European Geosciences Union. 
Lightning Imaging Sensor (LIS; Mach et al., 2007), however they are not able to provide continuous global coverage for all points on the Earth's surface. The need for a genuinely world-wide, ground-based network is therefore undeniable, particularly for the coverage of the oceans and regions of low population density or economic development.

The World Wide Lightning Location Network (WWLLN) is such a network, and has been operational since March 2003. It is a low-cost, real-time, ground-based network that is capable of detecting lightning anywhere on the globe with high temporal and spatial accuracy. In this study, the WWLLN performance is evaluated over a region in Ontario, Canada by comparing it to the Canadian Lightning Detection Network (CLDN), a national network established in 1998. This is the first comparison between the WWLLN and the CLDN.

\section{Lightning detection by the CLDN and the WWLLN}

The CLDN and the WWLLN have somewhat similar detection methods, however, due to the difference in the sensors and spectral bands employed, they have contrasting detection ranges, network location accuracy, and detection efficiency ratings.

\subsection{Description of the CLDN}

The CLDN was designed in 1997, and has been operated and managed by Environment Canada (EC) since 1998 (Dockendorff and Spring, 2005). It operates with line-of-sight detection of the ground wave, and only uses the first few microseconds of a lightning stroke in order to avoid interference with the sferic produced from the same lightning event (see Sect. 2.2). Unlike the WWLLN, which functions solely in the Very Low Frequency band (VLF; 3-30 kHz) to detect sferics, CLDN sensors use both VLF and the Low Frequency band (LF; $30-300 \mathrm{kHz}$ ) to detect ground waves. Attenuation is higher in the LF band, so the CLDN receivers must be placed a few hundred kilometers apart, much closer than the sensors of the WWLLN.

The objective of the CLDN was to provide a cloud-toground flash detection efficiency of better than $90 \%$ and less than $500 \mathrm{~m}$ location accuracy in its region of coverage (Dockendorff and Spring, 2005). This goal has been achieved for a peak current threshold of $5 \mathrm{kA}$ (Burrows et al., 2002). The network functions with 83 sensors distributed across the country, employing both Magnetic Direction Finding (MDF) and Time of Arrival (TOA) technologies; as of August 2009, it was composed of 27 IMPACTES, 30 LPATS-IV, 25 LS7000, and 1 LS7001 Vaisala sensors (Steve Kowalczyk, personal communication, August 2009). The Lightning Position and Tracking System (LPATS) sensors use TOA, and the Improved Accuracy from Combined Technology (IMPACT) and CG (cloud-to-ground) Enhanced
Lightning Sensors (LS7000/LS7001) both use TOA and MDF for lightning detection (Cummins et al., 1998b; Rakov and Uman, 2003). At the start of the period of interest for this paper (May 2008), the CLDN configuration was somewhat different. The CLDN was composed of 27 IMPACTES, 40 LPATS-IV, and 16 LS7000 sensors, and during the campaign period (May to August 2008), four of the LPATSIV sensors were upgraded to LS7000 sensors (Steve Kowalczyk, personal communication, August 2009). Similar upgrades have continued at CLDN sites since then.

A comparable local lightning detection network exists in the United States of America and is called the National Lightning Detection Network (NLDN). Together, these two networks comprise the North American Lightning Detection Network (NALDN). The performance and properties of the NLDN are described in detail by Cummins et al. (1998a,b) and Cummins and Murphy (2009). Figure 1 shows the configuration of the CLDN during the acquisition of the data used in this work, along with the locations of NLDN sensors.

\subsection{Description of the WWLLN}

The WWLLN is a real-time, world-wide, ground-based network operated by the University of Washington that can detect strong lightning strokes occurring anywhere in the world (Dowden et al., 2002; Lay et al., 2004; Jacobson et al., 2006; Rodger et al., 2005, 2006, 2009). The network was initiated with the intention of achieving global detection with a location accuracy of less than $10 \mathrm{~km}$ (Rodger et al., 2009). The WWLLN receivers operate in the VLF band and detect the lightning wave packet that propagates in the region between the Earth and the lower ionosphere, termed the EarthIonosphere Waveguide (EIWG). These wave packets propagate in particular waveguide modes (TE, TM or TEM), which effectively obscure the polarity of the parent lightning strokes. However, the VLF energy radiated is directly related to the peak current, and WWLLN expects to be able to report the energy per stroke by the end of 2010.

The signal is a wave train, called a sferic, that rises slowly from the noise background and lasts for roughly a millisecond or more. This complicates the detection of the sferic, for which instead of the trigger time of the signal being used to locate lightning, the Time of Group Arrival (TOGA) is employed, along with minimization methods comparable to those used in the TOA method. Details of the TOGA method, as well as updates to the algorithms and waveform criteria, are discussed in detail by Dowden et al. (2002) and Rodger et al. (2009). In this work, data processed with the new Stroke_B algorithm were used; Rodger et al. (2009) show that this algorithm improves the WWLLN stroke count globally by $63 \%$, and in some local regions by more than this.

In order to determine lightning locations, sferic detection takes advantage of the higher spectral power density and lower attenuation available in the VLF range than in higher frequency bands, enabling the receivers to be placed several 


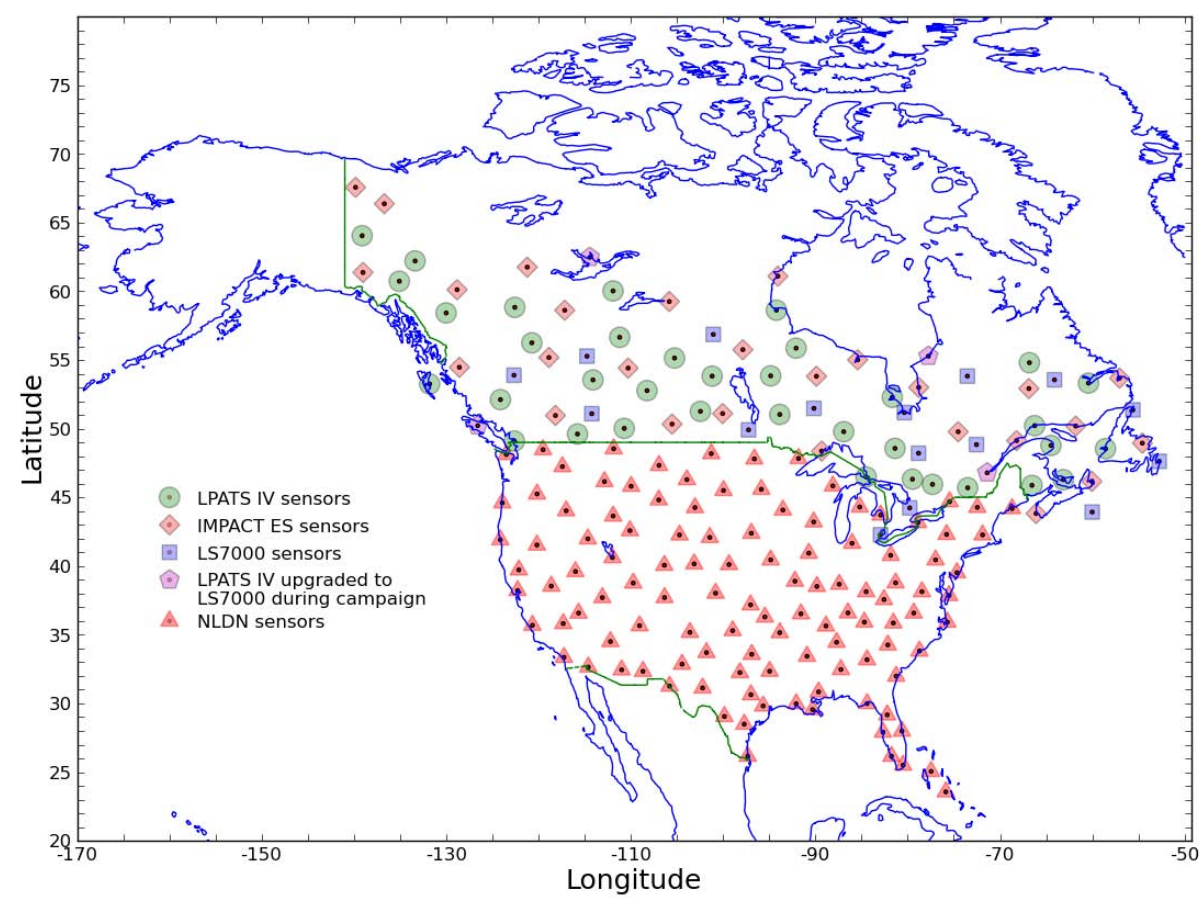

Fig. 1. Locations of the CLDN and NLDN sensors operational during acquisition of the data used in this work.

thousands of kilometers apart (Crombie, 1964). By comparing the WWLLN Darwin receiver's detected strokes against that of the WWLLN as a whole, Rodger et al. (2006) found that the detection efficiency of the sensor in the daytime decreases gradually with distance beyond $\sim 8000 \mathrm{~km}$ and is negligible after $\sim 14000 \mathrm{~km}$. At night, each sensor detects out to about 10000 to $12000 \mathrm{~km}$ with equal efficiency. Moreover, if the lightning locations are closer than $\sim 500 \mathrm{~km}$ to the sensor, the detection efficiency also drops. The WWLLN does not obtain good fits to the TOGA when there is significant power in the waveguide modes, such as the TEM mode, which are otherwise strongly attenuated with propagation distance. Thus, the TOGAs calculated from nearby strokes are often less well constrained, and therefore have errors too large to allow their inclusion in the WWLLN database.

At the time of writing, there were $40 \mathrm{WWLLN}$ receivers existing around the world to detect radio wave pulses in real time radiating from lightning strokes within the 6$22 \mathrm{kHz}$ VLF receiver band. However, during the campaign period there were only 29 active receivers as shown in Fig. 2; none of these were located in Canada. Each sensor consists of a 1.5-m whip antenna, a Global Positioning System (GPS) receiver, a VLF receiver, and a processing computer with Internet connection to enable transmission of the data to processing stations. The sensors are located on ferro-concrete buildings around the world because at VLF, they act as conductors and stay at ground potential, hence shielding the antenna from local man-made noise (Dowden et al., 2002). Moreover, in the receiver bandwidth, the vertical electric field from strong lightning dominates over power line noise, therefore, the locations of these receivers do not necessarily have to be in noise-free conditions (Lay et al., 2004).

After collecting the verified TOGA data together at the processing sites, residual minimization methods are used to create high quality data sets of lightning locations. The handling practice for the WWLLN data used in this paper ensures that the time residual for the data collected (indicating the quality of the fit to the data) is less than $30 \mu \mathrm{s}$ and that the lightning strokes are detected by at least five WWLLN VLF receiver stations (Rodger et al., 2009). This protocol differs from some previous studies that were performed early in the establishment of the network (Lay et al., 2004; Rodger et al., 2005), as comparisons to regional networks led to improvements in WWLLN data handling practices (Dr. Craig Rodger, personal communication, August 2009).

\section{Performance evaluation of the WWLLN}

In order to analyze the performance of the WWLLN, lightning stroke data obtained from this network using the most recent Stroke_B algorithm (Rodger et al., 2009) were compared to that from the CLDN. Both data sets were restricted to the grid box $41.7^{\circ} \mathrm{N}$ to $45.7^{\circ} \mathrm{N}$, and $77.4^{\circ} \mathrm{W}$ to $81.4^{\circ} \mathrm{W}$ between 1 May 2008 and 31 August 2008, as shown in Fig. 3. This grid box is defined by the location of the Toronto Atmospheric Observatory (TAO), $\pm 2^{\circ}$ north-south 


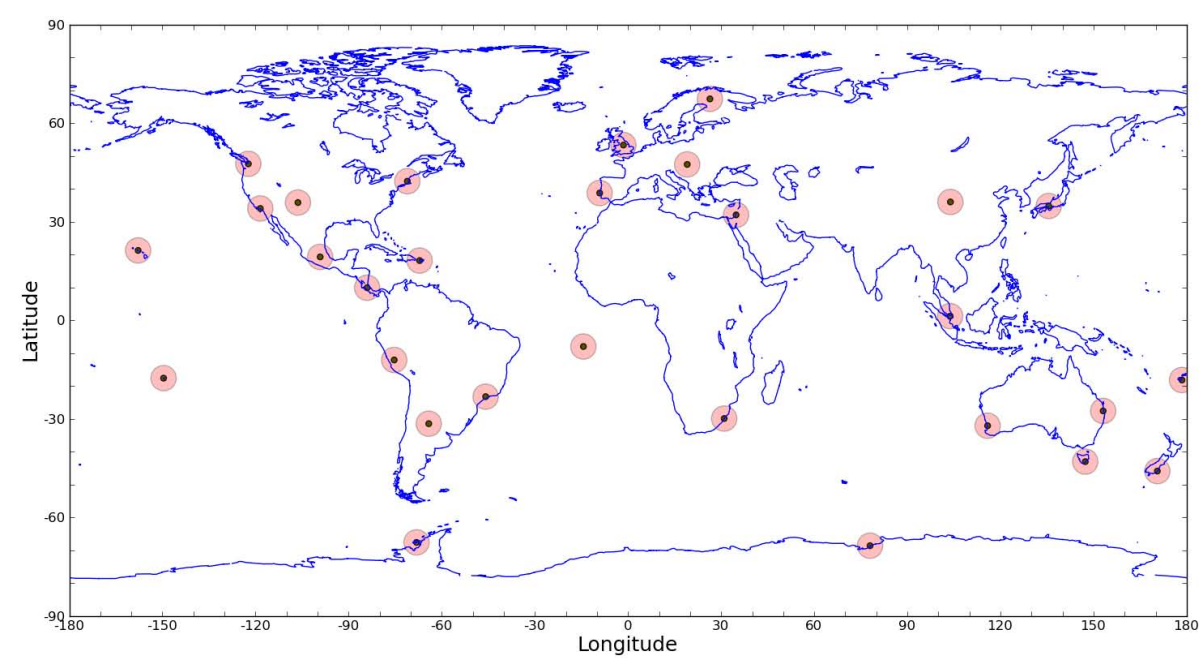

Fig. 2. Locations of the WWLLN sensors operational during acquisition of the data used in this work.

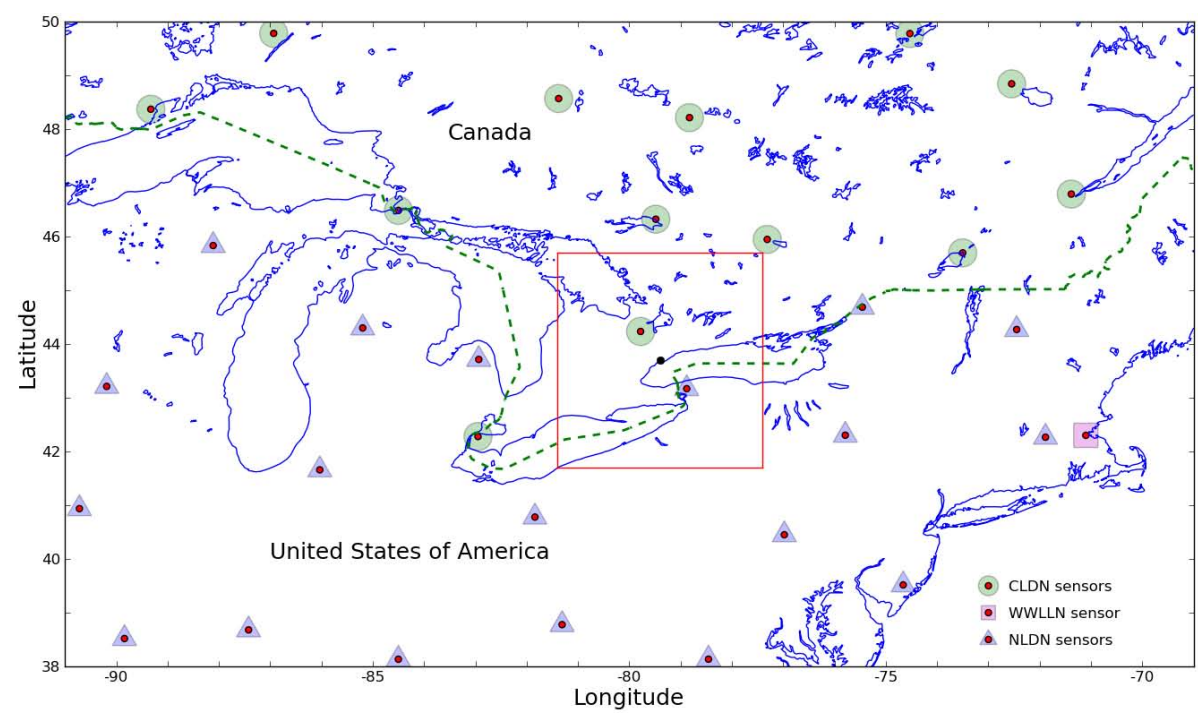

Fig. 3. The analysis region used in this study between May and August 2008, represented by the red box. The boundary is the coordinate box $41.7^{\circ} \mathrm{N}$ to $45.7^{\circ} \mathrm{N}$, and $77.4^{\circ} \mathrm{W}$ to $81.4^{\circ} \mathrm{W}$. It is centered around the Toronto Atmospheric Observatory (TAO) located at $43.7^{\circ} \mathrm{N}$ and $79.4^{\circ} \mathrm{W}$, and indicated by the black dot. The locations of nearby CLDN, WWLLN, and NLDN sensors are also indicated.

and $\pm 2^{\circ}$ east-west, in southern Ontario. This region was chosen because it experiences frequent lightning activity in the summer, hence the selection of four months in the summer of 2008. Note that the "CLDN" solution set provided by Environment Canada is generated using sensors in both the CLDN and the NLDN. The use of this larger data set reduces possible location errors due to the region of interest not being surrounded by CLDN sensors, which is the case for the grid box used in this work due to its location in southern Canada. The locations of nearby sensors from both the CLDN and the NLDN, along with those from the WWLLN, are also shown in Fig. 3.
During the campaign period, a total of 20605 WWLLN strokes and 677406 CLDN strokes were detected within the region of interest. Of the CLDN-detected strokes, 568152 $(\sim 84 \%)$ were identified as cloud-to-ground and 109254 $(\sim 16 \%)$ were identified as cloud strokes. The mean positive peak current of these CLDN-detected strokes (including both cloud-to-ground and cloud strokes) was $14.2 \mathrm{kA}$ and the mean negative peak current was $-16.6 \mathrm{kA}$. The peak current distribution for the strokes is shown in Fig. 4. Note that there exists a greater fraction of negative lightning strokes than positive as expected (Rakov and Uman, 2003).

To determine the detection efficiency of the WWLLN relative to the CLDN, shared events between the two 


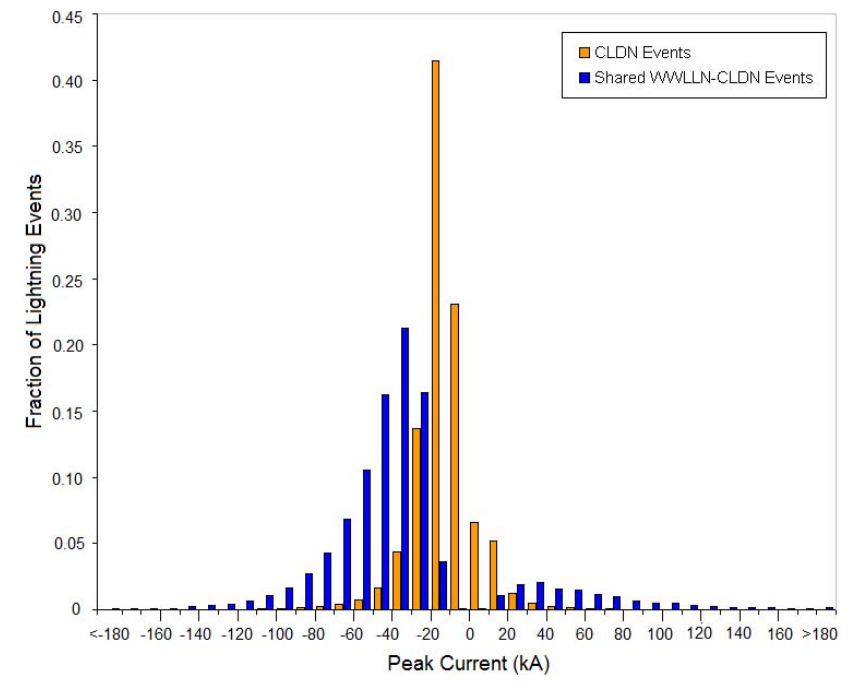

Fig. 4. Peak current distribution for the CLDN and the shared WWLLN-CLDN strokes as determined by the CLDN. Data are grouped into 10-kA bin-sizes, and the outermost bins indicate the number of strokes that are greater than $180 \mathrm{kA}$ in magnitude. The orange bars are all strokes detected by the CLDN while the blue bars are strokes shared between the CLDN and the WWLLN.

networks must be identified. Previous comparisons involving WWLLN and other regional lightning detection networks have used several different criteria to define shared strokes. Lay et al. (2004) and Rodger et al. (2005) defined shared strokes as those that were within $3 \mathrm{~ms}$ and $50 \mathrm{~km}$ of each other, Jacobson et al. (2006) ensured that strokes were within $1 \mathrm{~ms}$ and $100 \mathrm{~km}$ of each other, and Rodger et al. (2006) ensured that they were within $0.5 \mathrm{~ms}$ of each other. The latter criterion is the one adopted in this paper for two reasons. Firstly, as noted by Rodger et al. (2006), the WWLLN data are given to microsecond resolution, whereas the CLDN data are given to nanosecond resolution. Because of the high temporal resolution of the data, it is believed that a time criterion alone should be sufficient to characterize shared events. Secondly, following through with this criterion, it is observed that the mean time difference between these shared events (WWLLN - CLDN) was $-6.44 \mu$ s with a standard deviation of $35 \mu$ s, thus producing the time difference histogram shown in Fig. 5. Notice that $0.5 \mathrm{~ms}$ is considerably greater than three standard deviations of the distribution $(3 \times 35 \mu \mathrm{s}=105 \mu \mathrm{s})$. Initially, a spatial criterion of $50 \mathrm{~km}$ was also applied along with the time criterion in order to ensure that strokes considerably separated in space were not considered shared. It was found that this only eliminated 24 shared events and so this spatial criterion was dropped for the results presented here because it did not produce any significant effect.

Using the $0.5-\mathrm{ms}$ time criterion, 19128 of all the WWLLN-detected strokes were found to be shared with CLDN-detected strokes, thus giving the WWLLN a $2.8 \%$ stroke detection efficiency with respect to the CLDN.

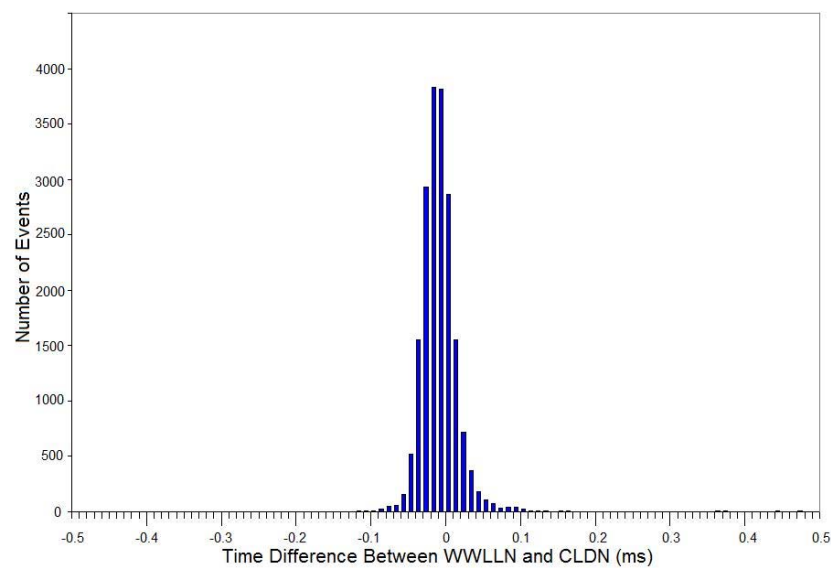

Fig. 5. Distribution of the time difference between the WWLLN and CLDN shared strokes (WWLLN - CLDN) using the 0.5-ms time criterion. Data are grouped into 0.01-ms bin-sizes.

Conversely, it was found that 18744 of the cloud-to-ground CLDN strokes and 669 of the cloud CLDN strokes were shared with WWLLN events. The combination of these shared CLDN events sums to 19413, creating a discrepancy of (19413-19 128=) 285 strokes. Upon further investigation, it was found that 281 of the shared WWLLN events match two CLDN events, and two of the shared WWLLN events match three CLDN events. Based on a calculation of the distance between the CLDN strokes that are shared with the same WWLLN stroke, none of the multiple shared events appear to be from the same CLDN stroke, however, all but two of them seem to be part of the same storm system. The mean positive peak current for the shared strokes was $59.2 \mathrm{kA}$ and the mean negative peak current was $-46.7 \mathrm{kA}$. The peak current distribution for these shared strokes is shown in Fig. 4 along with that from the CLDN data set alone.

The difference between the mean peak current of the entire CLDN data set and that of the shared data set (14.2 kA and $59.2 \mathrm{kA}$ respectively, for the mean positive currents; $-16.6 \mathrm{kA}$ and $-46.7 \mathrm{kA}$ respectively, for the mean negative currents) suggests that the WWLLN's current threshold for detection of lightning strokes is much higher than that of the CLDN. This also seems to be the case for the comparisons with the Brazil (Lay et al., 2004), New Zealand (Rodger et al., 2006), and Los Alamos (Jacobson et al., 2006) regional lightning detection networks. To further demonstrate the WWLLN current threshold, Fig. 6 shows the detection efficiency of the WWLLN relative to the CLDN, as a function of peak current in 5-kA bins. Notice that below the magnitude of $\sim 20 \mathrm{kA}$, the detection efficiency is negligible, but for high peak currents, the detection efficiency in the 5-kA bins is between $60 \%$ and $85 \%$, reaching $\sim 70 \%$ for the 5$\mathrm{kA}$ bins at $\pm 120 \mathrm{kA}$. The symmetry of the distribution indicates that the WWLLN detects both positive and negative strokes equally well as long as they are above the 20-kA peak 


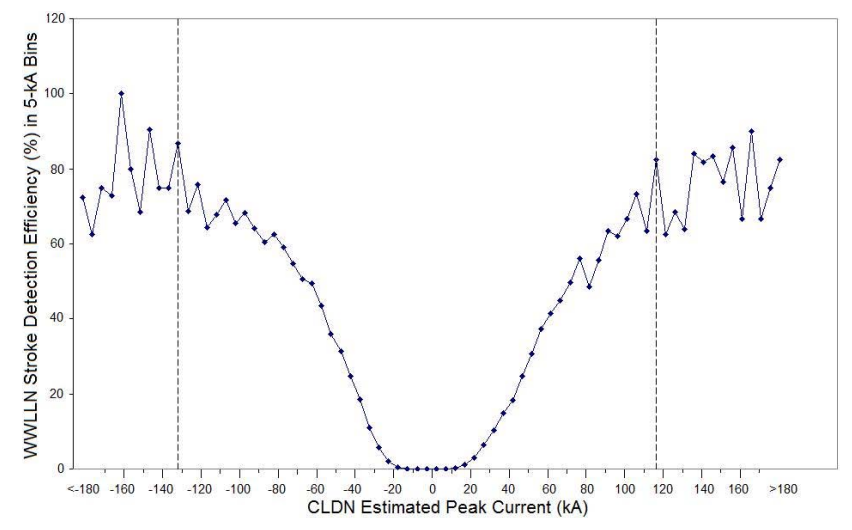

Fig. 6. WWLLN stroke detection efficiency distribution taking the CLDN as ground truth. Data are grouped into 5-kA bins and the outermost bins indicate the detection efficiency for strokes that are greater than $180 \mathrm{kA}$ in magnitude. The vertical dashed lines indicate bins that have fewer than 50 CLDN-detected strokes.

current threshold. The oscillations in peak current beyond the dashed vertical lines reflect the lack of statistical data to characterize the behavior in this current range (there are, on average, $\sim 9500$ CLDN-detected strokes in each bin, but beyond these dashed vertical lines, each has less than 50). In Table 1, the stroke detection efficiency of the WWLLN as a function of peak current threshold is summarized. This threshold is the minimum value of the peak current, so that the number of events in each entry includes all events whose peak current is greater than the given threshold. The detection efficiency clearly increases with the peak current threshold, having a value of $11.3 \%$ for $\pm 20 \mathrm{kA}$ increasing to $75.8 \%$ for $\pm 120 \mathrm{kA}$.

The same data, when grouped differently, can also be used to observe the effect of the changing ionosphere on the WWLLN detection efficiency. Figure 7 shows the same information as Fig. 6, but divided into two 12-h periods centered on local noon (solid red curve) and local midnight (dashed blue curve). The vertical lines again indicate the current range beyond which there is not enough statistical data to properly characterize the detection efficiency of the WWLLN (less than 25 CLDN strokes in each bin, whereas the average bin contains $\sim 4700$ CLDN-detected strokes). The three points indicating a detection efficiency greater than $100 \%$ lie beyond these lines and are the result of the shared data set having one more stroke than the CLDN data set for each of these bins. There is a noticeably higher detection efficiency for local midnight than local noon, however the 20-kA peak current threshold persists for both periods, as does the symmetric nature of the distribution. The changes in detection efficiency are attributed to the difference in the thickness of the ionospheric D-region between night and day. During the night, the D-region disappears, thus providing a clear path for the VLF waves to be reflected by the E-region back towards the ground. During the day, however, solar
Table 1. The stroke detection efficiency of the WWLLN as a function of peak current threshold.

\begin{tabular}{cccc}
\hline $\begin{array}{c}\text { Peak Current } \\
\text { Threshold (kA) }\end{array}$ & $\begin{array}{c}\text { Number of } \\
\text { Shared CLDN- } \\
\text { WWLLN Events }\end{array}$ & $\begin{array}{c}\text { Number of } \\
\text { CLDN Events }\end{array}$ & $\begin{array}{c}\text { WWLLN } \\
\text { Detection } \\
\text { Efficiency (\%) }\end{array}$ \\
\hline 120 & 439 & 579 & 75.8 \\
100 & 933 & 1302 & 71.7 \\
80 & 1995 & 3027 & 65.9 \\
60 & 4530 & 7960 & 56.9 \\
40 & 10241 & 26725 & 38.3 \\
20 & 18187 & 160545 & 11.3 \\
0 & 19128 & 677406 & 2.8 \\
\hline
\end{tabular}

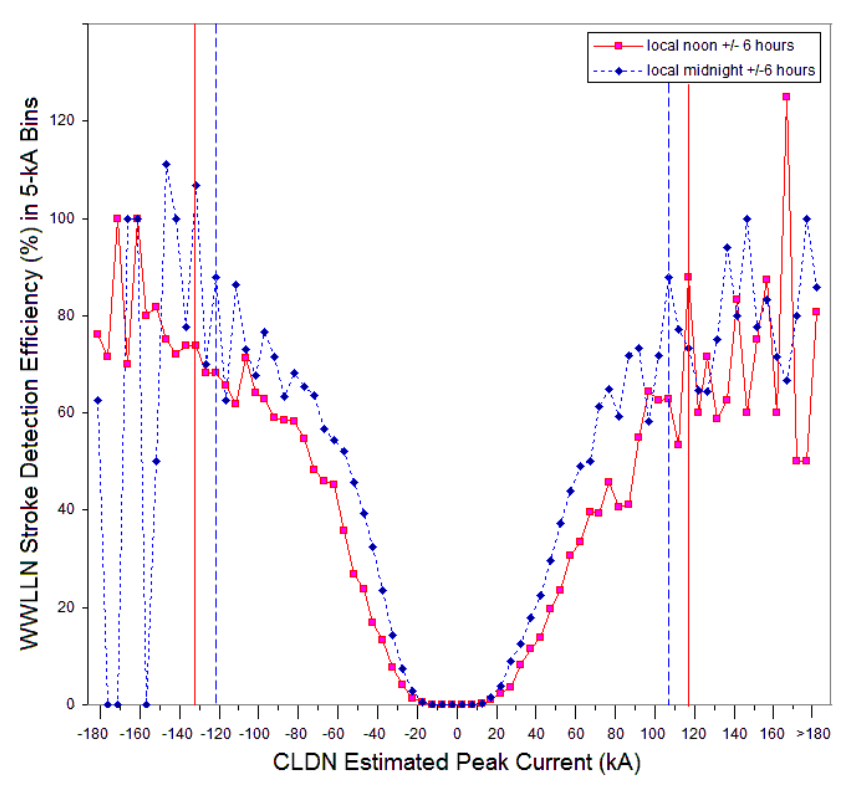

Fig. 7. Same as Fig. 6, except the data are now grouped into 12$\mathrm{h}$ periods centered on local noon (solid red curve) and local midnight (dotted blue curve). This demonstrates the effect of ionospheric changes on the detection efficiency of the WWLLN. Bins with fewer than $25 \mathrm{CLDN}$-detected strokes are indicated by vertical red solid lines and vertical blue dashed lines for strokes detected during local noon and local midnight, respectively.

radiation enhances the ionization of the ionosphere, producing the D-region, which increases the absorption of the VLF sferic energy upon each transit of the layer. A better approach for evaluating the diurnal dependence of the detection efficiency would use the solar zenith angle and define "day" and "night" such that they do not include twilight. The 12-h windows used in this study blur the day/night boundary, and as the season examined was summer at mid-latitudes, the window centered on local midnight includes significant periods of solar illumination. Thus, a stronger contrast in detection efficiency between day and night would be expected with the use of a solar zenith angle cutoff. 
The spatial accuracy of the shared strokes was determined by placing all the shared CLDN events at the origin (0, 0 ) and plotting the corresponding WWLLN events around this (WWLLN-CLDN). The mean latitudinal offset was $-3.14 \mathrm{~km}$ with a standard deviation of $5.91 \mathrm{~km}$, and the mean longitudinal offset was $1.62 \mathrm{~km}$ with a standard deviation of $6.71 \mathrm{~km}$, as shown in Fig. 8. Note that the CLDN locations are determined from direct line-of-sight ground wave propagation, whereas the WWLLN locations are determined from sferic propagation, which encounters varying ionospheric conditions along its path. Thus, the small bias observed in the WWLLN results with respect to the CLDN strokes is expected due to the difference in the propagation of the signals detected by the two networks. The mean absolute location accuracy was also evaluated, and is given by the mean of the distances between the shared strokes. Its value is $7.24 \mathrm{~km}$ with a standard deviation of $6.34 \mathrm{~km}$. The earliest study to evaluate the absolute location accuracy of the WWLLN was by Lay et al. (2004), who obtained a value of $20.25 \pm 13.5 \mathrm{~km}$. The difference between these results will be discussed in the next section.

Altogether, there were a total of 20605 strokes detected by WWLLN, and of these, 19128 were shared with the CLDN, leaving 1477 unshared WWLLN strokes. Examining these unshared events, 1466 of them occur within $50 \mathrm{~km}$ and $1 \mathrm{~h}$ of other CLDN events. Because the spatial dimension of a typical thunderstorm system ranges from $3 \mathrm{~km}$ to $>50 \mathrm{~km}$, and the lifetime of an individual cell in such a storm is of the order of one hour (Rakov and Uman, 2003), it can be assumed that these are indeed valid lightning strokes that were missed by the CLDN since its efficiency is not $100 \%$. Therefore, the total number of valid lighting strokes detected in this study is more likely to be 20594 .

The remaining 11 unshared strokes are considered "outliers"; these comprise a negligible $0.05 \%$ of the WWLLN events detected. Such events were also observed in past studies (Lay et al., 2004; Rodger et al., 2005; Jacobson et al., 2006). Lay et al. (2004) compared these outlier events to results obtained from a balloon campaign, and the regional network's raw data; Rodger et al. (2005) and Jacobson et al. (2006) both plotted the shared and outlier events and observed that they appeared to be part of the same storm system. Consequently, all of these studies reported that the outlier events were valid lightning strokes that were missed by the regional network due to its efficiency rating. This is also the conclusion assumed for the outlier events in this study. Moreover, if the CLDN region were expanded by $50 \mathrm{~km}$ on each side of the WWLLN grid region (the spatial dimension for a typical storm system), it is believed that the number of unshared and outlier events will be further reduced because the strokes close to the boundary of the WWLLN grid region will be treated appropriately when considering the validity of the unshared strokes. We have examined the 1477 unshared events more closely and found that 309 of them are within $20 \mathrm{~km}$ (chosen as approximately three standard deviations

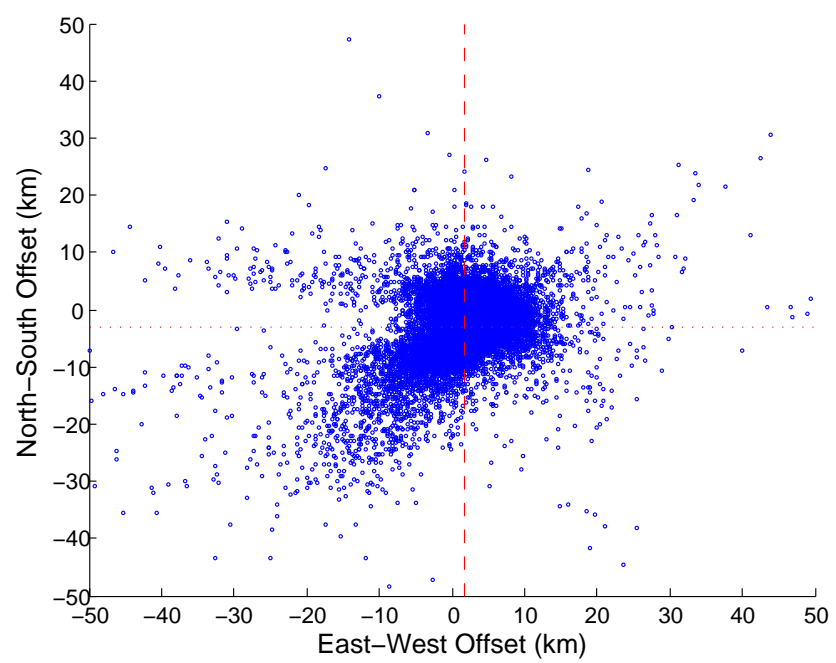

Fig. 8. Location offsets between the shared strokes, taking each CLDN stroke as the origin and plotting the corresponding WWLLN stroke relative to it (WWLLN - CLDN). The mean north-south offset is $-3.14 \mathrm{~km}$, displayed as the dotted red line, and the mean eastwest offset is $1.62 \mathrm{~km}$, displayed as the dashed red line.

in the mean spatial offset between shared events; see Table 2) of at least one of the boundaries of the grid box and 209 events are within $10 \mathrm{~km}$. So it is possible that these unshared WWLLN strokes have matching CLDN strokes that lie outside the grid box for which we have data. Assuming that all 309 strokes are in fact shared (but mis-categorized because of our fixed grid boundary) would give a total of 19437 valid shared strokes, and a detection efficiency of $2.9 \%$. We also note that if the total number of strokes detected by the WWLLN (20605), rather than the number of strokes shared with the CLDN (19 128) is used, the detection efficiency of the WWLLN increases slightly to $3.0 \%$.

\section{Comparison with past studies}

There have been several previous studies that have characterized the detection efficiency and location accuracy of WWLLN by comparing it to regional networks around the world (Lay et al., 2004; Rodger et al., 2005, 2006; Jacobson et al., 2006). The findings of these studies, along with those of this paper, are summarized in Table 2.

Lay et al. (2004) used a regional network in Brazil called the Brazil Integrated Network (BIN), and obtained a detection efficiency $(0.5 \%)$ that was less than a fifth of the value obtained in this study (2.8\%). Conversely, the mean absolute magnitude of the peak current they obtained for the shared strokes $(85.7 \mathrm{kA})$ was much greater than that obtained here $(48.4 \mathrm{kA})$, indicating that the current threshold of the WWLLN has decreased since that study. Furthermore, the error in the mean time difference between the shared strokes $(200 \mu \mathrm{s})$ was much larger than the three standard 
Table 2. Summary of WWLLN comparison studies.

\begin{tabular}{|c|c|c|c|c|c|}
\hline & Lay et al. (2004) & Rodger et al. (2005) & Rodger et al. (2006) & Jacobson et al. (2006) & Abreu et al. (this work) \\
\hline $\begin{array}{l}\text { Regional Network } \\
\text { Used for } \\
\text { Comparison }\end{array}$ & $\begin{array}{l}\text { BIN (Brazil Integrated } \\
\text { Network) }\end{array}$ & Kattron, in Australia & $\begin{array}{l}\text { NZLDN (New Zealand } \\
\text { Lightning Detection } \\
\text { Network) }\end{array}$ & $\begin{array}{l}\text { LASA (Los Alamos } \\
\text { Sferic Array), in Florida }\end{array}$ & $\begin{array}{l}\text { CLDN (Canadian } \\
\text { Lightning Detection } \\
\text { Network), in southern } \\
\text { Ontario }\end{array}$ \\
\hline $\begin{array}{l}\text { Data Acquisition } \\
\text { Dates }\end{array}$ & $\begin{array}{l}6,7,14,20,21 \text { March } \\
2003\end{array}$ & 13 January 2004 & $\begin{array}{l}1 \text { October } 2003- \\
31 \text { December } 2004\end{array}$ & $\begin{array}{l}27 \text { April - } \\
10 \text { September } 2004\end{array}$ & $\begin{array}{l}1 \text { May - } \\
31 \text { August } 2008\end{array}$ \\
\hline Region of Interest & $\begin{array}{l}40-55^{\circ} \mathrm{W} \\
15-25^{\circ} \mathrm{S}\end{array}$ & Southeast Australia & $\begin{array}{l}165-180^{\circ} \mathrm{E} \\
34-49^{\circ} \mathrm{S}\end{array}$ & $\begin{array}{l}\leq 400 \mathrm{~km} \text { radius circle, } \\
\text { centred at } 29^{\circ} \mathrm{N}, 82^{\circ} \mathrm{W}\end{array}$ & $\begin{array}{l}41.7-45.7^{\circ} \mathrm{N} \\
77.4-81.4^{\circ} \mathrm{W}\end{array}$ \\
\hline $\begin{array}{l}\text { Number of WWLLN } \\
\text { Receivers }\end{array}$ & 11 & 18 & 20 & 19 & 29 \\
\hline $\begin{array}{l}\text { WWLLN Handling } \\
\text { Practice }\end{array}$ & $\begin{array}{l}\text { TOA algorithm, } \\
\text { Time residual } \leq 20 \mu \mathrm{s}, \\
\geq 4 \text { receiving stations }\end{array}$ & $\begin{array}{l}\text { TOGA algorithm, } \\
\text { Time residual } \leq 20 \mu \mathrm{s}, \\
\geq 4 \text { receiving stations }\end{array}$ & $\begin{array}{l}\text { TOGA algorithm, } \\
\text { Time residual } \leq 30 \mu \mathrm{s}, \\
\geq 5 \text { receiving stations }\end{array}$ & $\begin{array}{l}\text { TOGA algorithm, } \\
\text { Time residual } \leq 30 \mu \mathrm{s}, \\
\geq 5 \text { receiving stations }\end{array}$ & $\begin{array}{l}\text { TOGA Stroke_B } \\
\text { algorithm, } \\
\text { Time residual } \leq 30 \mu \mathrm{s}, \\
\geq 5 \text { receiving stations }\end{array}$ \\
\hline $\begin{array}{l}\text { Number of } \\
\text { Regional Network } \\
\text { Strokes }^{\text {a }}\end{array}$ & $\mathrm{G}=63893$ & $\begin{array}{l}\text { Total }=20182 \\
\mathrm{G}=19313(95.7 \%), \\
\mathrm{C}=869(4.3 \%)\end{array}$ & $\begin{array}{l}\text { Total }=224221 \\
\mathrm{G}=204411(91.2 \%), \\
\mathrm{C}=19,810(8.8 \%)\end{array}$ & $\begin{array}{l}\text { Total }=8923316 \\
\mathrm{G}=4196004(47.0 \%) \\
\mathrm{C}=4,727,312(53.0 \%)\end{array}$ & $\begin{array}{l}\text { Total }=677406 \\
\mathrm{G}=568152(83.9 \%), \\
\mathrm{C}=109254(16.1 \%)\end{array}$ \\
\hline $\begin{array}{l}\text { Mean Peak } \\
\text { Current of } \\
\text { Regional Network }^{b}\end{array}$ & $|\bar{i}|=33.3 \mathrm{kA}$ & $|\bar{i}|=13.8 \mathrm{kA}$ & $\begin{array}{l}\mathrm{G}:|\bar{i}|=23.4 \mathrm{kA}, \\
\mathrm{C}:|\bar{i}|=16.3 \mathrm{kA}\end{array}$ & $\begin{array}{l}\mathrm{c}_{(}(-) \bar{i} \sim-18 \mathrm{kA} \\
\mathrm{c}_{(+) \bar{i}} \sim 9 \mathrm{kA}\end{array}$ & $\begin{array}{l}(-) \bar{i}=-16.6 \mathrm{kA} \\
(+) \bar{i}=14.2 \mathrm{kA} \\
|\bar{i}|=16.2 \mathrm{kA}\end{array}$ \\
\hline $\begin{array}{l}\text { Number of Strokes } \\
\text { Detected by } \\
\text { WWLLN }\end{array}$ & 671 & 11609 & 13459 & 75884 & 20605 \\
\hline $\begin{array}{l}\text { Criteria for Shared } \\
\text { Events }\end{array}$ & $\begin{array}{l}\leq 3 \mathrm{~ms} \text { time difference, } \\
\leq 50 \mathrm{~km} \text { spatial separation }\end{array}$ & $\begin{array}{l}\leq 3 \mathrm{~ms} \text { time difference } \\
\leq 50 \mathrm{~km} \text { spatial separation }\end{array}$ & $\leq 0.5 \mathrm{~ms}$ time difference & $\begin{array}{l}\leq 1 \mathrm{~ms} \text { time difference, } \\
\leq 100 \mathrm{~km} \text { spatial } \\
\text { separation }\end{array}$ & $\leq 0.5 \mathrm{~ms}$ time difference \\
\hline $\begin{array}{l}\text { Number of Shared } \\
\text { Strokes }^{d}\end{array}$ & Total $=289(0.5 \%)$ & Total $=5006(24.8 \%)$ & $\begin{array}{l}\text { Total }=6113(2.7 \%), \\
\mathrm{G}=5923(2.9 \%) \\
\mathrm{C}=190(1.0 \%)\end{array}$ & $\begin{array}{l}\text { Total }=71362(0.8 \%) \\
{ }^{\mathrm{e}} \mathrm{G}=52728 \\
{ }^{\mathrm{e}} \mathrm{C}=21437\end{array}$ & $\begin{array}{l}\text { Total }=19,128(2.8 \%), \\
\mathrm{f}_{\mathrm{G}}=18744, \\
{ }^{\mathrm{f}} \mathrm{C}=669\end{array}$ \\
\hline $\begin{array}{l}\text { Mean Peak Current } \\
\text { for Shared Events }{ }^{b}\end{array}$ & $|\bar{i}|=85.7 \mathrm{kA}$ & $|\bar{i}|=14.3 \mathrm{kA}$ & $\begin{array}{l}\mathrm{G}:|\bar{i}|=46.2 \mathrm{kA}, \\
\mathrm{C}:|\bar{i}|=41.2 \mathrm{kA}\end{array}$ & $\begin{array}{l}\mathrm{c}_{(}(-) \bar{i} \sim-31 \mathrm{kA} \\
\mathrm{c}_{(+) \bar{i}} \sim 23 \mathrm{kA}\end{array}$ & $\begin{array}{l}(-) \bar{i}=-46.7 \mathrm{kA}, \\
(+) \bar{i}=59.2 \mathrm{kA}, \\
|\bar{i}|=48.4 \mathrm{kA}\end{array}$ \\
\hline $\begin{array}{l}\text { Mean Time } \\
\text { Difference for } \\
\text { Shared Events }\end{array}$ & $\bar{t}=60 \pm 200 \mu \mathrm{s}$ & $\bar{t}=490 \mu \mathrm{s}$ & $\bar{t}=32 \mu \mathrm{s}$ & NA & $\begin{array}{l}\bar{t}=-6.44 \mu \mathrm{s} \\
\sigma=35 \mu \mathrm{s}\end{array}$ \\
\hline $\begin{array}{l}\text { Mean Spatial Deviation } \\
\text { for Shared Events } \mathrm{g} \text { : } \\
\text { Longitude }\end{array}$ & $\bar{x}=+7.3 \mathrm{~km}$ & $\begin{array}{l}\bar{x}=-0.9 \mathrm{~km} \\
\sigma=2.7 \mathrm{~km}\end{array}$ & NA & ${ }^{\mathrm{c}} \bar{x} \sim 2 \mathrm{~km}$ & $\begin{array}{l}\bar{x}=1.62 \mathrm{~km} \\
\sigma=6.71 \mathrm{~km}\end{array}$ \\
\hline $\begin{array}{l}\text { Mean Spatial Deviation } \\
\text { for Shared Events }{ }^{\mathrm{g}} \text { : } \\
\text { Latitude }\end{array}$ & $\bar{y}=+3.2 \mathrm{~km}$ & $\begin{array}{l}\bar{y}=+2.8 \mathrm{~km} \\
\sigma=3.5 \mathrm{~km}\end{array}$ & NA & $\mathrm{c}_{\bar{y}} \sim-5 \mathrm{~km}$ & $\begin{array}{l}\bar{y}=-3.14 \mathrm{~km} \\
\sigma=5.91 \mathrm{~km}\end{array}$ \\
\hline $\begin{array}{l}\text { Number of } \\
\text { Unshared Events }^{\mathrm{h}}\end{array}$ & $382(56.9 \%)$ & $6603(56.9 \%)$ & $7346(54.6 \%)$ & $4522(6.0 \%)$ & $1477(7.2 \%)$ \\
\hline $\begin{array}{l}\text { Criteria for } \\
\text { Outlier Events }\end{array}$ & $\begin{array}{l}>30 \mathrm{~km} \text { spatial } \\
\text { coincidence }\end{array}$ & $\begin{array}{l}\text { If not observed with } \\
\text { other campaigns }\end{array}$ & NA & $\begin{array}{l}>100 \mathrm{~km} \text { spatial, } \\
>200 \mathrm{~ms} \text { time } \\
\text { coincidence }\end{array}$ & $\begin{array}{l}>50 \mathrm{~km} \text { spatial, } \\
>1 \mathrm{~h} \text { time coincidence }\end{array}$ \\
\hline $\begin{array}{l}\text { Number of Outlier } \\
\text { Events }^{\mathrm{h}}\end{array}$ & $7(1.0 \%)$ & $6586(56.7 \%)$ & NA & $996(1.3 \%)$ & $11(0.05 \%)$ \\
\hline
\end{tabular}

a Total strokes as well as number of cloud-to-ground $[\mathrm{G}]$ and cloud strokes $[\mathrm{C}]$ (\% with respect to total).

$\mathrm{b}$ Positive $[+]$ and negative $[-]$ mean peak current $[\bar{i}]$ and when available, mean absolute current $[|\bar{i}|]$.

c Obtained visually from histograms in Fig. 4 of Jacobson et al. (2006).

${ }^{\mathrm{d}}$ For total, cloud-to-ground [G], and cloud [C] strokes, \% given with respect to the regional network as ground truth, where possible.

e Does not add to the total. In this study, there were (74 165-71 362=) 2803 WWLLN events that had both cloud-to ground [G] and cloud [C] LASA events within \pm 1 ms

${ }^{\mathrm{f}}$ Does not add to the total. In this study, there were 283 WWLLN events that had multiple CLDN events within $\pm 0.5 \mathrm{~ms}$.

$\mathrm{g} \sigma$ is a standard deviation, $\bar{t}, \bar{x}, \bar{y}$ are the mean time, longitude, and latitude differences (WWLLN - CLDN), respectively.

$\mathrm{h} \%$ given with respect to the total WWLLN events detected.

$\mathrm{NA}=$ not applicable - used when no data are available.

Atmos. Meas. Tech., 3, 1143-1153, 2010

www.atmos-meas-tech.net/3/1143/2010/ 
deviations of this study $(3 \times 35 \mu \mathrm{s}=105 \mu \mathrm{s})$, and as mentioned in Sect. 3, they obtained a mean location accuracy of $20.25 \pm 13.5 \mathrm{~km}$ whereas the value acquired in this study is $7.24 \mathrm{~km}$ with a standard deviation of $6.34 \mathrm{~km}$. These differences are, however, expected because Lay et al. (2004) described their results as a "worse case scenario". That study was performed when the WWLLN had just begun and was functioning with only 11 receivers that were all located more than $7000 \mathrm{~km}$ from the region of interest. The WWLLN handling practice also differed, using a $20 \mu$ s maximum time residual with each stroke being detected by at least four receiving stations. This WWLLN protocol has since changed, as noted in Sect. 2.2.

Rodger et al. (2005) used the Kattron regional network in Australia for comparison with the WWLLN. The detection efficiency $(24.8 \%)$ turned out to be much larger than that of any other study, there did not seem to be a current threshold, the mean time difference was large $(490 \mu \mathrm{s})$, and more than half of the events detected (56.7\%) could not be accounted for and were thus labeled as outlier events. These results may be due to several factors. The data was collected in a single day (13 January 2004), so a malfunctioning of the regional Kattron network over the region of interest is plausible. There also could have been unusual sferic propagation conditions at that time and location (Dr. Craig Rodger, personal communication, September 2009). Furthermore, this study was done when the WWLLN was still in its infancy, and so the network may not have been as reliable as its updated versions. In order to resolve this issue, a more in-depth look at the Rodger et al. (2005) results is required, including an analysis of their raw data and the atmospheric conditions present at the time.

The criterion for shared events in this paper matches that of Rodger et al. (2006), who compared the WWLLN to the New Zealand Lightning Detection Network (NZLDN). The detection efficiency (2.7\%) obtained by Rodger et al. (2006) is very similar to that obtained in this study (2.8\%). However, the number of unshared events recorded was much larger in that study (54.6\% of the WWLLN strokes detected) and was not investigated. This may be due to excellent WWLLN sensor coverage for the region of interest (see Fig. 2), leading to the WWLLN detecting many strokes that were missed by the NZLDN (Rodger et al., 2006). Unlike the previous study by Rodger et al. (2005), these data were acquired over a period of 15 months (1 October 2003 to 31 December 2004), thus, problems with the regional network must be ruled out. Once again, examining the raw data as well as further analyzing the unshared events would be key to understanding how this issue has arisen.

Finally, Jacobson et al. (2006) obtained similar results to those achieved in this study using five months of data from the Los Alamos Sferic Array (LASA) in Florida. They found a WWLLN detection efficiency of $0.8 \%$ (compared to $2.8 \%$ acquired here), and observed that $1.3 \%$ of the WWLLN strokes were outlier events (compared to $0.05 \%$ in our study).
Theirs is the only study, in addition to ours, that reported single WWLLN strokes shared with multiple local network strokes. It is interesting to note that they detected roughly equal numbers of cloud and cloud-to-ground strokes. This is because LASA is able to detect both types of events equally well, as long as they are of a comparable current magnitude (Jacobson et al., 2006). This may explain the low detection efficiency observed in that study, as cloud lightning strokes typically have a low peak current and so the WWLLN is less likely to detect them due to its relatively high peak current threshold (see Fig. 6).

\section{Conclusions}

Regional ground-based lightning detection networks exist all over the world, however, they do not extend far beyond national borders. Satellite-based lightning sensors provide valuable data but cannot provide continuous global coverage. The requirement for a truly world-wide lightning detection network is therefore unquestionable and has numerous applications. The WWLLN is such a low-cost, real-time, ground-based network, which has been operational since March 2003, and whose aim is to provide better than $10-\mathrm{km}$ location accuracy globally.

In this paper, both the CLDN and the WWLLN were briefly described, and the performance of the WWLLN was evaluated between May and August 2008 over a region centered on southern Ontario, Canada by using the CLDN as ground truth. It was observed that the WWLLN detected $2.8 \%$ of all 677406 CLDN lightning strokes, increasing to $3.0 \%$ if all WWLLN strokes are used. By analyzing the peak currents, the data suggests that the peak current threshold for the WWLLN is $\sim 20 \mathrm{kA}$, much higher than the 5kA threshold of the CLDN. The detection efficiency of the WWLLN increases with peak current threshold, with values of $11.3,56.9$, and $75.8 \%$ for peak currents greater than 20 , 60 , and $120 \mathrm{kA}$, respectively. The changing ionosphere was observed to affect the WWLLN detection efficiency, resulting in higher detection efficiency at local midnight than at local noon due to the presence and absence of the ionospheric D-region during the day and night, respectively.

The shared events between the two networks were characterized with a $\leq 0.5 \mathrm{~ms}$ time criterion, leading to a mean absolute location accuracy of $7.24 \mathrm{~km}$ with a standard deviation of $6.34 \mathrm{~km}$. These results were compared to four previous studies performed using other regional lightning detection networks to assess the WWLLN. They were summarized and found to be generally consistent with the results obtained in this paper. In conclusion, the goal for a WWLLN cloudto-ground location accuracy of less than $10 \mathrm{~km}$ has been met. With the addition of more WWLLN receivers, the detection efficiency of the network should continue to improve. 
Acknowledgements. Funding for this research was provided by the Natural Sciences and Engineering Research Council of Canada (NSERC). D. Abreu also received financial support from the Department of Physics at the University of Toronto. The authors thank Environment Canada (EC) for their generous permission to use Canadian Lightning Detection Network data and software, and Serge Deschamps, Maria Petrou, Steve Kowalczyk, and Kelsey Spring in particular, for providing us with the CLDN data and site locations. The authors also thank the World Wide Lightning Location Network (http://wwlln.net), a collaboration among more than 40 universities and institutions, for providing the WWLLN lightning location data used in this paper. We are deeply appreciative of Erin Lay (Los Alamos National Laboratory), Craig Rodger (University of Otago), David Hudak (EC), Mike Leduc (EC), and William Burrows (EC) for answering questions and providing advice. K. Strong would also like to thank Richard Dowden (University of Otago) for introducing her to VLF lightning detection and installing a system at TAO. We thank David Dockendorff, Colin Price, and an anonymous referee for their helpful comments on the manuscript.

Edited by: H. Worden

\section{References}

Burrows, W. R., King, P., Lewis, P. J., Kochtubajda, B., Snyder, B., and Turcotte, V.: Lightning occurrence patterns over Canada and adjacent United States from lightning detection network observations, Atmos.-Ocean, 40(1), 59-81, 2002.

Choi, Y., Wang, Y., Zeng, T., Martin, R. V., Kurosu, T. P., and Chance, K.: Evidence of lightning $\mathrm{NO}_{\mathrm{x}}$ and convective transport of pollutants in satellite observations over North America, Geophys. Res. Lett., 32, L02805, doi:10.1029/2004GL021436, 2005.

Christian, H. J., Blakeslee, R. J., Boccippio, D. J., Boeck, W. L., Buechler, D. E., Driscoll, K. T., Goodman, S. J., Hall, J. M., Koshak, W. J., Mach, D. M., and Stewart, M. F.: Global frequency and distribution of lightning as observed from space by the Optical Transient Detector, J. Geophys. Res., 108(D1), 4005, doi:10.1029/2002JD002347, 2003.

Crombie, D. D.: Periodic fading of VLF signals received over long paths during sunrise and sunset, J. Research National Bureau of Standards, Radio Sci., 68D, 27-34, 1964.

Cummins, K. L., Krider, E. P., and Malone, M. D.: The U.S. National Lightning Detection Network and applications of cloud-toground lightning data by electric power utilities, IEEE T. Electromagn. C., 40(4), 465-480, 1998a.

Cummins, K. L., Murphy, M. J., Bardo, E. A., Hiscox, W. L., Pyle, R. B., and Pifer, A. E.: A combined TOA/MDF technology upgrade of the U.S. National Lightning Detection Network, J. Geophys. Res., 103(D8), 9035-9044, 1998b.

Cummins, K. L. and Murphy, M. J.: An overview of lightning location systems: History, techniques, and data uses, with an indepth look at the U.S. NLDN, IEEE T. Electromagn. C., 51(3), 499-518, 2009.
Dockendorff, D. and Spring, K.: The Canadian Lightning Detection Network-Novel approaches for performance measurement and network management, Proceedings, WMO Technical Conference on Instruments and Methods of Observation (TECO), Bucharest, Romania, 2005.

Dowden, R. L., Brundell, J. B., and Rodger, C. J.: VLF lightning location by time of group arrival (TOGA) at multiple sites, J. Atmos. Sol.-Terr. Phy., 64, 817-830, 2002.

Höller, H., Betz, H.-D., Schmidt, K., Calheiros, R. V., May, P., Houngninou, E., and Scialom, G.: Lightning characteristics observed by a VLF/LF lightning detection network (LINET) in Brazil, Australia, Africa and Germany, Atmos. Chem. Phys., 9, 7795-7824, doi:10.5194/acp-9-7795-2009, 2009.

Jacobson, A. R., Holzworth, R., Harlin, J., Dowden, R., and Lay, E.: Performance assessment of the World Wide Lightning Location Network (WWLLN), using the Los Alamos Sferic Array (LASA) as ground truth, J. Atmos. Ocean. Tech., 23, 1082-1092, 2006.

Lagouvardos, K., Kotroni, V., Betz, H.-D., and Schmidt, K.: A comparison of lightning data provided by ZEUS and LINET networks over Western Europe, Nat. Hazards Earth Syst. Sci., 9, 1713-1717, doi:10.5194/nhess-9-1713-2009, 2009.

Lay, E. H., Holzworth, R. H., Rodger, C. J., Thomas, J. N., Pinto Jr., O., and Dowden, R.: WWLL global lightning detection system: Regional validation study in Brazil, Geophys. Res. Lett., 31, L03102, doi:10.1029/2003GL018882, 2004.

Mach, D. M., Christian, H. J., Blakeslee, R. J., Boccippio, D. J., Goodman, S. J., and Boeck, W. L.: Performance assessment of the Optical Transient Detector and Lightning Imaging Sensor, J. Geophys. Res., 112, D09210, doi:10.1029/2006JD007787, 2007.

Martin, R. V., Sauvage, B., Folkins, I., Sioris, C. E., Boone, C., Bernath, P., and Ziemke, J.: Space-based constraints on the production of nitric oxide by lightning, J. Geophys. Res., 112, D09309, doi:10.1029/2006JD007831, 2007.

Price, C.: Will a drier climate result in more lightning?, Atmos. Res., 91(2-4), 479-484, 2009.

Rakov, V. A. and Uman, M. A.: Lightning: Physics and Effects, Cambridge University Press, UK, 2003.

Rodger, C. J., Brundell, J. B., and Dowden, R. L.: Location accuracy of VLF World-Wide Lightning Location (WWLL) network: Post-algorithm upgrade, Ann. Geophys., 23, 277-290, doi:10.5194/angeo-23-277-2005, 2005.

Rodger, C. J., Werner, S., Brundell, J. B., Lay, E. H., Thomson, N. R. Holzworth, R. H., and Dowden, R. L.: Detection efficiency of the VLF World-Wide Lightning Location Network (WWLLN): initial case study, Ann. Geophys., 24, 3197-3214, doi:10.5194/angeo-24-3197-2006, 2006.

Rodger, C. J., Brundell, J. B., Holzworth, R. H., and Lay, E. H.: Growing detection efficiency of the World Wide Lightning Location Network, Am. Inst. Phys. Conf. Proc., Coupling of thunderstorms and lightning discharges to near-Earth space: Proceedings of the Workshop, 23-27 June 2008, Corte, France, 1118, 15-20, doi:10.1063/1.3137706, 2009.

Schlegel, K., Diendorfer, G., Thern, S., and Schmidt, M.: Thunderstorms, lightning and solar activity - Middle Europe, J. Atmos. Sol.-Terr. Phy., 63, 1705-1713, 2001. 
Sioris, C. E., McLinden, C. A., Martin, R. V., Sauvage, B., Haley, C. S., Lloyd, N. D., Llewellyn, E. J., Bernath, P. F., Boone, C. D., Brohede, S., and McElroy, C. T.: Vertical profiles of lightning-produced $\mathrm{NO}_{2}$ enhancements in the upper troposphere observed by OSIRIS, Atmos. Chem. Phys., 7, 42814294, doi:10.5194/acp-7-4281-2007, 2007.
Volland, H.: Atmospheric Electrodynamics, Springer-Verlag, New York, 1984.

Williams, E. R.: The Schumann Resonance: A global tropical thermometer, Science, 256, 1184-1187, 1992. 